\author{
Per G. Broman \\ Director Environment Stora Corporate Research \\ Sweden
}

\begin{abstract}
Solid residuals form a significant part of the flow of materials in forest industry processes. These residuals are important sources of energy, primarily, and are therefore efficiently utilized. Only a small proportion of the residuals is deposited. Developments are moving toward an even greater degree of utilization of the residuals' potential value.

The paper reviews the way STORA uses its resources, the residuals that are generated and how they are utilized. It also intends to provide a picture of how work on residuals forms one part of the environmental quality work that STORA sums up in the word Ecobalance.
\end{abstract}

\title{
STORA
}

STORA is one of the largest forest products companies in the world. The group is one of Sweden's largest export companies with operations in some 20 countries. STORA's operations are based on forest raw materials. From this it produces sawn timber and pulp, which is processed into graphic papers, board and packaging paper. STORA's sales during 1996 totaled SEK 45,161 million (approximately 5,860 million $\$$ ). The group employs approximately 20,600 people.

STORA's industrial operations consist of kraft mills, sulfite mills, mechanical pulp mills, paper mills and sawmills at 30 different locations. Most of these facilities are integrated in different ways. All facilities have their own environmental agenda based on environmental surveys of the facilities and the group's environmental targets. The overall environmental target is to be in ecological balance. 


\section{RESOURCE USE}

The way in which the forest industry uses its raw materials is characterized by the desire to attain high yield. As much as $95 \%$ of a $\log$ can be utilized, either as products or as energy. The fact that so much is utilized can be attributed to the collaboration between sawmills, pulp and paper mills and board plants on utilizing the raw materials. Almost all grades and sizes of timber can be made use of and the by-products used to almost one hundred percent. The chips from the sawmill become raw materials for the pulp industry and the bark and sawdust are used as fuel. The residuals from the pulp industry, mainly bark and black liquors, are also used as fuel.

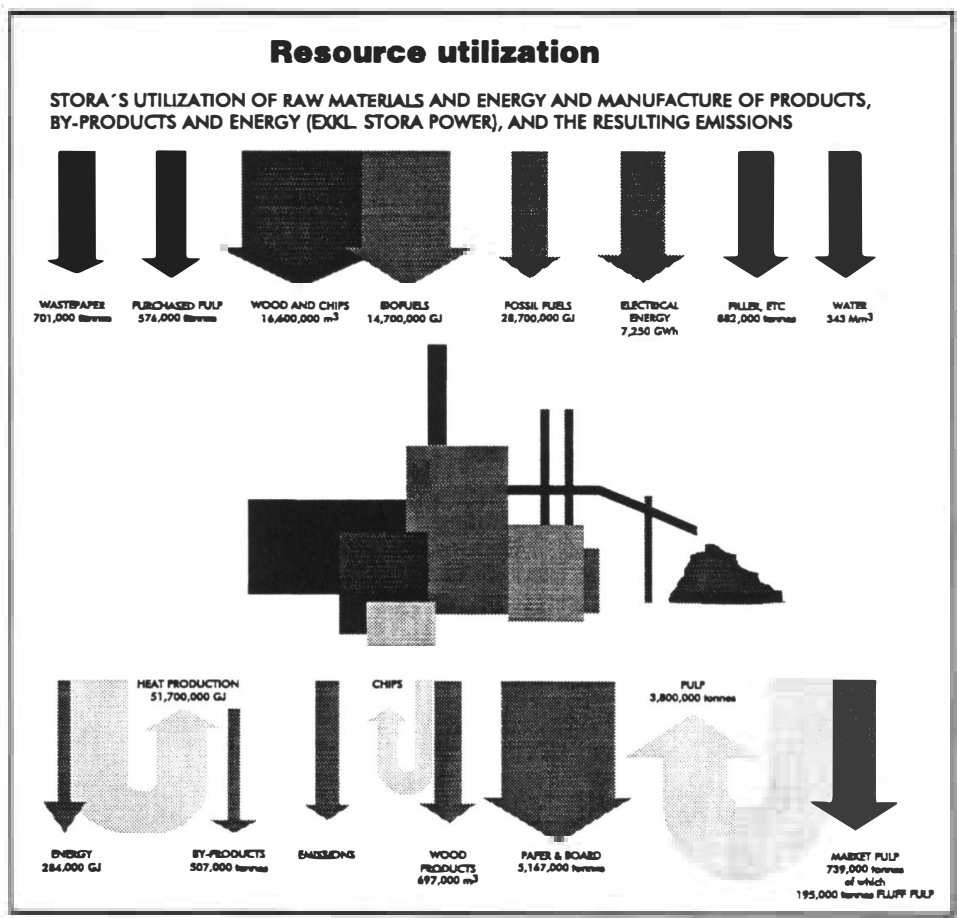

Fig. 1

STORA's utilization of raw materials and the resulting generation of products, byproducts and emissions is illustrated in Figure 1. As can be seen, the resource use is based on a significant integration of the flows of pulp, chips and energy.

Fuel utilization for the production of heat and power respectively, is illustrated in Figures 2 and 3. Energy efficiency programs are run at the mills, aiming at minimizing energy consumption and minimizing the use of fossil fuels. 
Fuels utilized for STORA's heat production and sfeam purchased in 1996.

Tołal consumption $80,500,000 \mathrm{GJ}$

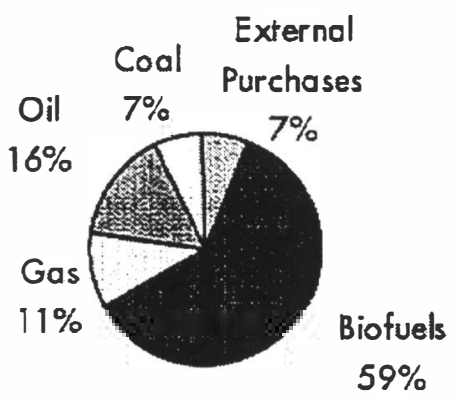

Fig. 2

Fuels utilized for STORA's power production (excluding Stora Power) and power purchased in 1996. Total consumption $9,400 \mathrm{GWh}$

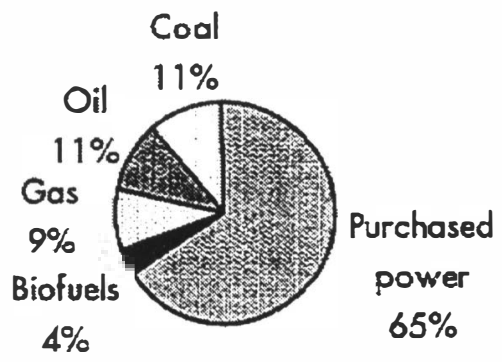

Fig. 3 


\section{ECOBALANCE}

STORA uses the term Ecobalance to define the objective of its environmental quality work. Ecobalance requires that;

- Forest shall be managed on a sustainable basis, maintaining a high volume of wood production while also preserving biological diversity.

- Wood products, pulp, paper and board, shall be produced using resourceefficient methods while fully utilizing raw materials. Any emissions that occur should be so low that normal biological activity, including human activity can be maintained even in the vicinity of a production facility.

- Product development shall focus on achieving maximum process efficiency combined with the lowest possible consumption of resources. Product design should be aimed at minimizing the amount of materials used.

- Fiber shall be recycled into new products as often as is practicable, after which it can be utilized as an environmentally compatible energy source. The extent of recycle must consider all aspects of the environment so that suboptimizations are not created anywhere within the forest products cycle.

- Transportation shall be regarded as an integral part of product life-cycles and therefore be included in environmental programs.

- Suppliers of goods and services shall be encouraged to engage in active environmental improvements throughout the forest industry product cycle.

It is STORA's view that the Ecobalance concept has to be effectively communicated with all relevant stakeholders. It is only when Ecobalance is well understood and demonstrated in real life that the credibility associated with the concept will materialize. For this to happen, the companies profitability requirements must also be fulfilled.

\section{Tools to Achieve Ecobalance}

The work towards Ecobalance within several fields has been progressing for many years. Ecobalance has nearly been reached on some points, while more work remains to be done on others. To fully reach Ecobalance, STORA has concluded that a few tools are of specific importance. The most significant ones are: i) The introduction and use of efficient environmental management systems throughout the group, ii) development of specific additional technical knowledge, iii) the effective application of the group's collective experience and knowledge by encouraging group wide communication and full employee participation, and iv) communication and co-operation with other industrial organizations, interest groups and government agencies.

\section{Environmental Management Systems}

STORA's environmental policy states that all operations should introduce environmental management systems, compatible with EMAS; EU's voluntary system for environmental management of industrial operations. The two main reasons 
for this decision are the potential of the system to work as a driver for continual improvements and that EMAS involves openness and public reporting. STORA was the first forest industry to be registered for EMAS in Germany and in Sweden. At present (September, 1997) eight units have attained EMAS-registration and according to plan, most of the group's operations will do so before the end of 1998. For non-European units, the requirement is for ISO 14001-certification plus the required elements of public openness, that presently distinguishes EMAS from ISO 14001.

One feature of the environmental management systems that is of specific interest is the requirement to identify the most significant environmental aspects of the operations and address these in setting targets for the continual improvement work. This may carry the environmental quality work far beyond the limits set by the traditional approach. For example, there is a possibility to include both local, regional and global factors in these assessments. Consequently, there is a real opportunity to work towards improving the Ecobalance, avoiding the suboptimizations that normally result from the traditional environmental permitting processes. STORA is presently working on developing the suitable tools to define and rank the most significant environmental aspects of the operations, including waste management. A Life Cycle Analysis (LCA) based approach shows the most promise.

\section{RESIDUALS}

The residuals produced at the mills are generally divided into branch -specific and general residuals. The various residuals appear at well-defined locations in the mill and can thus be kept apart. Figure 4 shows a general picture of the flows of residuals, generated at an integrated pulp and paper mill.

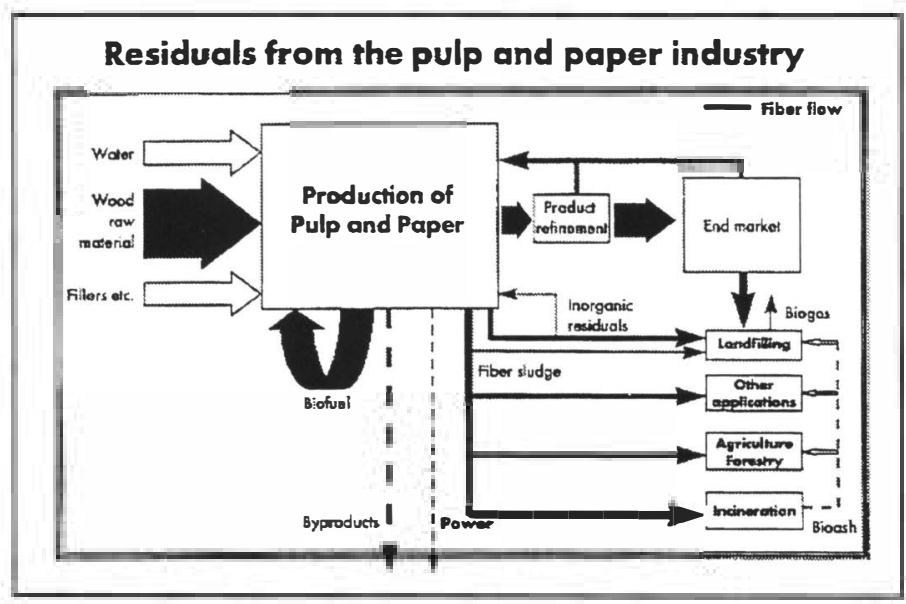

Fig. 4 
The branch-specific residuals are dominant in terms of quantity. They comprise black liquors, bark and wood-room waste, dust and ash from different boilers, sludge from causticizing plants and effluent treatment plants together with lime sludge, waste acids and foreign matter brought into the process by raw materials. The branch -specific residuals vary depending on type of production and type of treatment equipment.

At the pulp mills large quantities of bark are generated. Soot and ash are formed during incineration in oil and solid-fuel boilers. In chemical pulp production , cooking liquors are used and recycled. These are evaporated and incinerated, allowing the chemicals to be reused. In sulfate mills, lime sludge is obtained which is reburnt to lime. Inorganic material in the wood raw material, lime and other chemicals are enriched in the green liquor sludge. The residual acid generated in the production of the bleaching chemical chlorine dioxide is used in the mill.

The mills have sedimentation plants to separate fibers. At a number of pulp mills there are also biological treatment plants. In the newsprint mills the water is treated not only mechanically but also biologically and often chemically. The non-integrated paper mills and recycled paper mills are generally equipped with both mechanical and chemical treatment processes. The mechanical, biological and chemical treatment plants create large quantities of sludge.

At many recycling mills using printed paper, printing inks are separated using chemicals and form deinking sludge. The recycling mills also separate impurities such as plastic, wire etc., which arrive with the raw material.

Residuals of the various mixtures used for coating paper occur when coating mixtures are being exchanged and when reservoirs are cleaned.

At the mills, residuals of a more general nature are also produced. These may comprise various packagings, non-returnable pallets, old process equipment and construction waste. A small proportion of these general residuals is comprised of so-called hazardous waste such as waste oil, solvents, laboratory waste and leftover paints.

\section{THE HANDLING OF BRANCH-SPECIFIC RESIDUALS}

Efforts have been greatly intensified in recent years in the forest products industry to reduce the quantities of residuals deposited. The following review is mainly based on a survey of the Swedish forest products industry, Reference 1 below. In sulfate pulp mills of today 96-97 percent of the cooking chemicals are recovered. The lime sludge produced in the chemical cycle (approx. $500 \mathrm{~kg}$ per tonne of pulp) is converted in the lime sludge kiln into calcium oxide. Small quantities are used in landfill. Residual acid formed in the production of chlorine dioxide is recycled into the process, for example to cover sulfur losses.

Approx. 94 per cent of the residuals from the paper and pulp industry are used as fuel. These residual products consist mainly of black liquors, bark and sludge. 
The black liquors are burnt in recovery furnaces. The energy produced in this way forms an important part of the heat balance in the mills.

The treatment of bark has radically changed as prices for energy have risen. Nowadays all bark is burnt to produce steam. The only exception to this is the bark waste that occurs during handling in the mill yards and that contains so much gravel and stone that it is practically impossible to burn. These quantities are calculated at 4-5 per cent of the total quantity of bark.

At several mills, fiber sludge is reused direct in production after special treatment. In certain cases the fiber sludge is sold to other mills.

At quite a number of mills some of the fiber sludge is burnt in the solid fuel boilers. How successful this incineration is depends what type of sludge is being burnt and on the design of the boiler. Paper mill sludge rich in ash and chemical sludges may cause problems.

A small proportion of the residuals (1.6 per cent) is recycled or reused. Small quantities of biological sludge are composted and used as a soil improver or to cover landfill sites. Sometimes composted materials are regained from old landfills giving the landfills a longer useful life.

The residuals deposited in landfills, i.e. the residuals that are actually waste, amount to six per cent of the total volume. The majority of this is in the form of ash and green liquor sludge from the caustification process at the sulfate mills.

One example of how the volumes of waste deposited in landfills have been possible to reduce can be illustrated by developments at Stora Gruvön pulp and paper mill in Sweden, see Figure 5. The principal step taken here was the installation of a bark furnace.

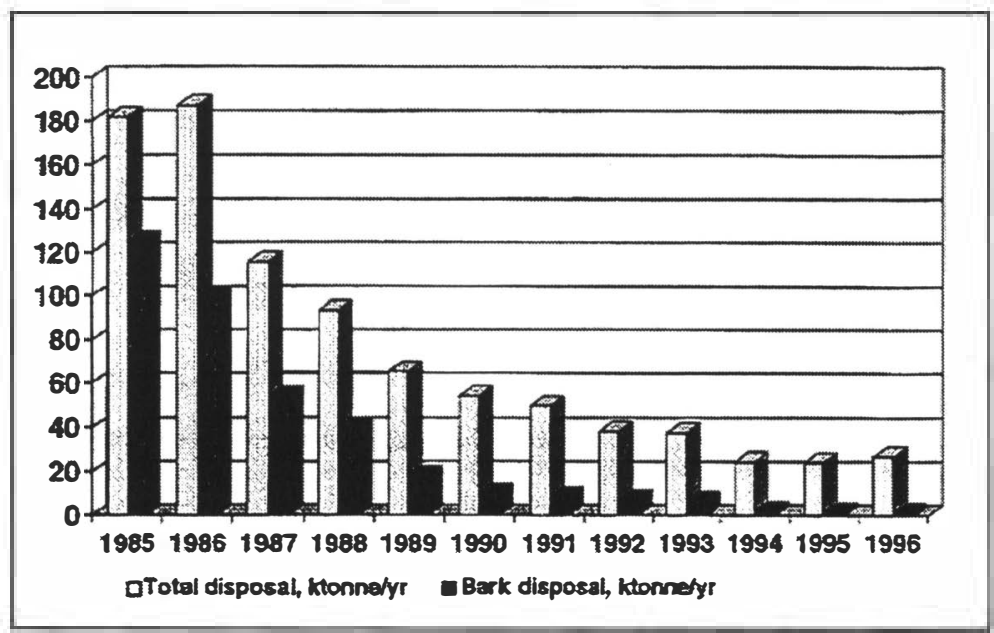

Fig. 5 
Another example from a STORA mill can be taken from Stora Celbi pulp mill in Portugal and concerns the effects of improved handling of fiber waste from screening and from effluent treatment, see Figure 6.

Development work is currently in progress at STORA mills and at Corporate Research to find ways to be able to reduce landfilling even more. Work is being focused partly on reducing the generation of residuals and partly on finding environmentally compatible uses for the residuals still produced.

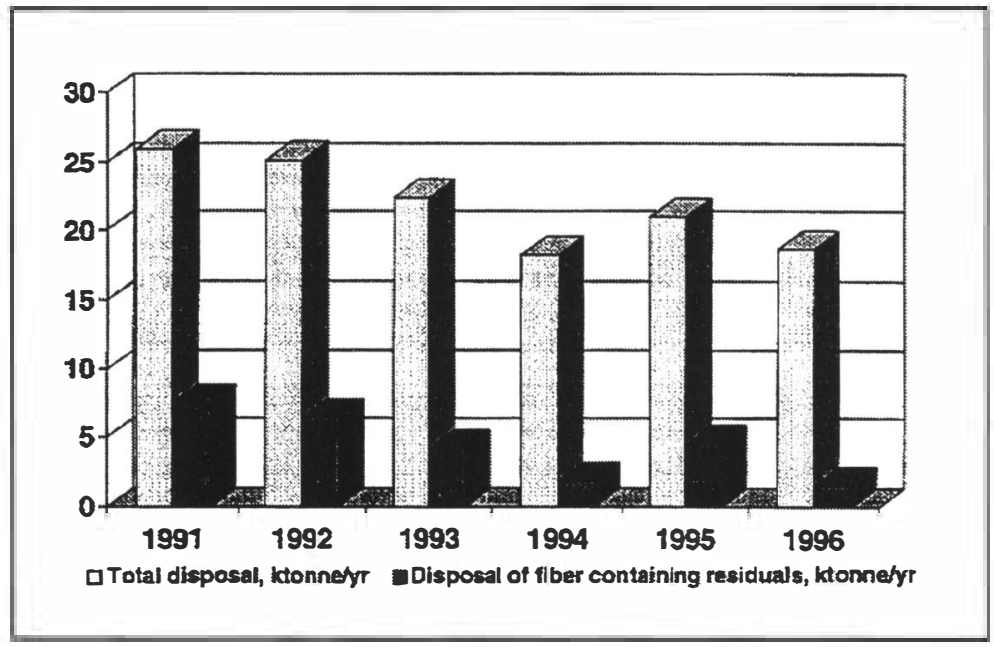

Fig. 6

Some examples of the current projects are the following:

- Dewatering and energy extraction from sludges.

- Return of ash, lime sludge and black sludge to forest ecosystems.

- Use of lime sludge and ash in the production of cement, concrete and bricks.

- Use of ashes for forest road construction.

- Use of lime sludge as fertilizer in agriculture.

- Liming of lakes and streams.

- Use of sludge for covering of disposal sites.

In line with Ecobalance principles we are seeking solutions that are based on a holistic view of the process and the environment.

\section{CONTROL MEANS FOR ENVIRONMENTAL QUALITY WORK}

The forest products industry is well positioned to attain Ecobalance. Major development work has taken place within the industry to reduce the direct environmental impact caused by earlier practices. This work has given extremely sat- 
isfactory results. In many aspects the operations at STORA's plants are close to being in Ecobalance. In certain cases some work remains to be able to attain this balance. In our on-going pro-environmental work that we are determined on carrying out, new and better instruments will be needed to make it possible to determine the optimum allocation of resources.

In certain aspects of this work we have reached the level after which continued efforts would be unreasonably expensive and the environmental benefits slight. On the other hand the more comprehensive view means that new areas can be identified for environmental quality work. One such example is the transportation sector, which STORA now consistently includes in the Ecobalance concept.

The new methods of working that are now developing mean that traditional proenvironmental work controlled by the authorities and based on the Environmental Protection Act is supplemented by pro-environmental work initiated by industry, based on holistic principles and focused on continual improvement. It would seem that the door is wide open for rational pro-environmental work in the future. Unfortunately the situation is not quite as simple or optimistic as that but has been made more complex by an increase in new political initiatives in the form of fiscal controls.

In theory, fiscal controls and incentives, for example to reduce emissions, could be seen as beneficial for both industry and society as a whole. But the waste sector in particular can provide illustrations of the fact that this is not always the case in practice. The waste tax that is being prepared for enforcement from mid 1998 does admittedly introduce "incentives", but the incentive it actually produces is only to be able to influence cost increases for the operations. This does not create resources for pro-environmental work. Instead corporations are forced to redeploy resources, perhaps from sectors that could be more rewarding in a wider environmental perspective, to a sector that has been given priority in an unnatural way.

\section{CONCLUSION}

The forest products industry is based on renewable raw materials and the operations are largely characterized by eco-cycle processes. About 95 per cent of the tree trunk can be utilized in producing sawn timber, pulp and paper as well as for the production of energy.

Liquors, bark and sludges from treatment plants are the principal residuals in the pulp and paper industry. Most of them are recycled, principally in the form of chemicals and energy. Only some 6 per cent of the total volume of residuals is deposited as landfill.

Major efforts are being made to reduce landfilling even more. A total landfill stop is however not a self-evident target. The handling of residuals must be seen in the holistic perspective that should characterize all work on environmental quality and that takes into account all the different stages in the life-cycle of a 
product. Within STORA this aspiration to a holistic view of the environment is summarized in the concept of Ecobalance.

The introduction of "incentives" in the form of taxes and duties to control the work done and measures taken by industry on residuals and waste will not necessarily lead environmental quality work in the right direction.

\section{REFERENCES}

MiljöInfo från Skogsindustriema.(1995) In Swedish. (Environmental Survey of the Swedish Forest Industries). Skogsindustriema.

STORA Environmental Report 1996. 